\title{
Histamine Induces Alzheimer's Disease-Like Blood Brain Barrier Breach and Local Cellular Responses in Mouse Brain Organotypic Cultures
}

\author{
Jonathan C. Sedeyn, ${ }^{1}$ Hao Wu, ${ }^{1}$ Reilly D. Hobbs, ${ }^{2}$ Eli C. Levin, ${ }^{1,3}$ \\ Robert G. Nagele, 3,4 and Venkat Venkataraman ${ }^{1,2}$ \\ ${ }^{1}$ Graduate School of Biomedical Sciences, Rowan University, Stratford, NJ 08084, USA \\ ${ }^{2}$ Department of Cell Biology, Rowan School of Osteopathic Medicine, Stratford, NJ 08084, USA \\ ${ }^{3}$ Biomarker Discovery Center, New Jersey Institute for Successful Aging, Rowan University School of Osteopathic Medicine, \\ Stratford, NJ 08084, USA \\ ${ }^{4}$ Department of Geriatrics and Gerontology, Rowan University School of Osteopathic Medicine, Stratford, NJ 08084, USA
}

Correspondence should be addressed to Venkat Venkataraman; venkatar@rowan.edu

Received 21 August 2015; Revised 30 October 2015; Accepted 8 November 2015

Academic Editor: Wiep Scheper

Copyright (C) 2015 Jonathan C. Sedeyn et al. This is an open access article distributed under the Creative Commons Attribution License, which permits unrestricted use, distribution, and reproduction in any medium, provided the original work is properly cited.

\begin{abstract}
Among the top ten causes of death in the United States, Alzheimer's disease (AD) is the only one that cannot be cured, prevented, or even slowed down at present. Significant efforts have been exerted in generating model systems to delineate the mechanism as well as establishing platforms for drug screening. In this study, a promising candidate model utilizing primary mouse brain organotypic $(\mathrm{MBO})$ cultures is reported. For the first time, we have demonstrated that the MBO cultures exhibit increased blood brain barrier (BBB) permeability as shown by IgG leakage into the brain parenchyma, astrocyte activation as evidenced by increased expression of glial fibrillary acidic protein (GFAP), and neuronal damage-response as suggested by increased vimentin-positive neurons occur upon histamine treatment. Identical responses-a breakdown of the BBB, astrocyte activation, and neuronal expression of vimentin-were then demonstrated in brains from $\mathrm{AD}$ patients compared to age-matched controls, consistent with other reports. Thus, the histamine-treated MBO culture system may provide a valuable tool in combating AD.
\end{abstract}

\section{Introduction}

As the most common form of dementia, Alzheimer's disease (AD) is currently affecting over 5.5 million people in the United States and more than 35 million worldwide $[1,2]$. The hallmark of the disease is progressive cognitive decline that results in loss of language/communication skills, difficulty in learning, loss of memory, and alterations in personality/mood [3-5]. The pathological changes seen in $\mathrm{AD}$ include synaptic loss, dendrite retraction, neuronal cell death, inflammation, astrocyte activation, blood-brain barrier (BBB) breakdown, and the accumulation of amyloid peptide 1-42 (A $\beta 42)$ within neurons and plaques throughout the hippocampus and cerebral cortex [6-12]. It has been noticed that breakdown of the BBB is a particularly important development in $\mathrm{AD}$ progression, as it allows for the leakage of damaging humoral elements into the brain parenchyma $[7,13,14]$.

The BBB is comprised of specialized vascular endothelial cells that are connected to one another via tight junctions. These endothelial cells are different from those in other parts of the mammalian body in that they lack fenestrations and therefore do not allow for free exchange of solutes between the blood and the brain parenchyma $[15,16]$. Additionally, astrocytic foot processes wrap around the blood vessels and play an important role in allowing endothelial cells to form and maintain their normally protective, tight seal [17]. When $\mathrm{BBB}$ breach occurs in the $\mathrm{AD}$ brains, it allows for the extravasation of blood-borne $A \beta 42$, brain-reactive autoantibodies, and inflammatory factors into the normally 
immune-privileged brain parenchyma [18-20]. Access of the previously excluded and potentially damaging bloodborne plasma elements to the brain interstitium results in disruption of brain homeostasis, impaired neuronal function, and eventually neuronal loss [7, 21-23]. These deleterious effects on neurons are apparently buffered by activation of neuronal repair mechanisms, one of which involves neuronal expression of vimentin. Vimentin is an intermediate filament protein that is found primarily in endothelial cells and developing neurons $[24,25]$. Vimentin expression in neurons has been linked temporally and spatially to dendrite repair in neurons of the cerebral cortex in $\mathrm{AD}$ and mouse brains subjected to traumatic injury [26]. Furthermore, injury or disease of the CNS, such as $\mathrm{AD}$, causes gliosis, which is characterized by activation of astrocytes and an increased expression of glial fibrillary acidic protein (GFAP) in these cells [27-29]. Therefore, BBB breakdown has been assigned as a key event in initiating damage and damage responses in both neurons and glial cells in AD.

While the deleterious effects of BBB breakdown are well documented, its origin remains unclear. Several molecules have been implicated, such as bradykinin, nitric oxide, oxygen radicals, and histamine [16]. Among these, histamine is a proinflammatory mediator derived from the amino acid histidine [30]. It is present throughout the mammalian body, predominantly localized to mast cell granules and basophils. Histamine also acts as a neurotransmitter and is released by histaminergic neurons of the tuberomamillary nucleus of the posterior hypothalamus [31]. Upon injury or trauma, an inflammatory response occurs and causes the release of histamine [16, 32], which then induces the BBB breach [33]. Several in vivo studies have shown that histamine, whether applied luminally or abluminally to microvasculature of the brain, increases BBB permeability by opening the interendothelial cell tight junctions [33-37]. Moreover, histamine is also shown to induce a swelling of perivascular glial foot processes when applied luminally via carotid artery infusion $[38,39]$. While histamine has been previously shown to induce BBB permeability in vivo, it is not yet known if it could cause a similar effect in vitro leading to generation of additional brain pathologies, for example, the neuronal and glial cell responses seen in neurodegenerative diseases such as $\mathrm{AD}$.

We chose primary mouse brain organotypic $(\mathrm{MBO})$ slice cultures as the model system, which has shown promise in assessing the response of brain cells to a wide variety of external stimuli $[40,41]$. In this study, we report that histamine elicits responses in $\mathrm{MBO}$ cultures that include a breakdown of the BBB as shown by IgG leakage into the brain parenchyma, astrocyte activation as evidenced by increased expression of GFAP and a neuronal damage-response as suggested by increased vimentin expression in these cells. We demonstrate that these changes are also observed in the brains of $\mathrm{AD}$ patients, consistent with earlier reports. Therefore, we propose that the histamine-treated MBO slice culture system may provide an attractive option to analyze cellular changes and responses observed in $\mathrm{AD}$ patients as well as to screen potential drug candidates for AD.

\section{Materials and Methods}

2.1. Ethics Statement. All experiments were conducted in compliance with the NIH guidelines and in accordance with protocols approved by the Institutional Review Board and Institutional Animal Care and Use Committee at Rowan University, School of Osteopathic Medicine.

2.2. Antibodies. Human IgG antibodies (polyclonal, Cat. number BA-3000, diluted at $1: 2000$ ) and mouse IgG antibodies (polyclonal, Cat. number BA-9200, diluted at 1:2000) were obtained from Vector Laboratories (Foster City, CA). GFAP antibodies were obtained from Millipore (Billerica, MA; polyclonal, Cat. number AB5804, diluted at $1: 1000$ ). Vimentin antibodies were obtained from Sigma (Saint Louis, MO; monoclonal, Cat. number V6630, diluted at 1:200). The specificity of the antibodies has been demonstrated earlier [26].

2.3. Animals. C57BL/6J mice were obtained from Jackson Laboratories (Bar Harbor, ME) and used at 9 months of age. Mice were maintained on ad libitum food and water with 12hour light/dark cycle in an AAALAC-accredited vivarium.

2.4. Primary Mouse Brain Organotypic Cultures. Primary mouse brain organotypic cultures were prepared as described previously [26]. Briefly, the brains were removed from C57BL/6 mice $(n=8)$ and cut to either $1 \mathrm{~mm}$ or $2 \mathrm{~mm}$ thickness coronally using a tissue chopper. The brain slices were then placed in medium containing 25\% inactivated horse serum, 25\% Hanks' BSS, 50\% DMEM, and $25 \mathrm{mg} / \mathrm{L}$ penicillin-streptomycin (Invitrogen, Carlsbad, CA) in 6well culture dishes and maintained for 30 minutes at room temperature. The brain slices were then moved to either fresh media (control) or fresh media containing $450 \mu \mathrm{M}$ histamine (Sigma, Saint Louis, MO, Cat. number H7125-1G) in 6-well culture dishes for 1 hour at $37^{\circ} \mathrm{C}$ in a $5 \% \mathrm{CO}_{2}$ enriched atmosphere. The brain slices were processed for immunohistochemistry as described below.

The MBO slices were stored in $4 \%$ PFA overnight at $4^{\circ} \mathrm{C}$ and processed according to previously published protocols [42-44]. The brain slices were then infiltrated with $30 \%$ sucrose in PBS overnight at $4^{\circ} \mathrm{C}$ under constant, gentle agitation. Using a Leica cryostat, $12 \mu \mathrm{m}$ thick frozen sections were cut, mounted onto Fisher Super Frost Plus slides, and air dried. The slides were stored until use.

2.5. Human Brain Tissue. Brain tissue from patients with sporadic $\mathrm{AD}(n=21)$ and age-matched, neurologically normal individuals $(n=13)$ were obtained from the Harvard Brain Tissue Resource Center (Belmont, MA), the Cooperative Human Tissue Network (Philadelphia, PA), the UCLA Tissue Resource Center (Los Angeles, CA), and Slidomics (Cherry Hill, NJ). Postmortem intervals were less than 24 hours and pathological confirmation of $\mathrm{AD}$ was evaluated according to the criteria defined by the National Institute on Aging and the Reagan Institute Working Group on Diagnostic Criteria for the Neuropathological Assessment of AD [45]. AD tissues 
displayed amyloid plaques and neurofibrillary tangles, and control tissues exhibited no gross pathology and minimal localized microscopic AD-like neuropathology. Tissues were processed for routine paraffin embedding and sectioning according to established protocols $[46,47]$.

2.6. Immunohistochemistry. Immunohistochemistry for the paraffin-embedded tissues was carried out as previously described $[46,47]$. Briefly, tissues were deparaffinized using xylene and then rehydrated through a graded series of decreasing concentrations of ethanol. Next, protein antigenicity was enhanced by microwaving sections in citrate buffer. The paraffin-embedded tissues were then processed in the same way as the frozen sections described below.

Immunohistochemistry for the frozen sections was carried out as previously described [26, 42-44]. Briefly, tissues were rehydrated with PBS for 2 minutes. The endogenous peroxidase was quenched by treating sections with $0.3 \%$ $\mathrm{H}_{2} \mathrm{O}_{2}$ for 30 minutes. First, sections were incubated in blocking serum for 30 minutes and then treated with primary antibodies at appropriate dilutions for 1 hour at room temperature. Next, sections were thoroughly rinsed with PBS and incubated with biotin-labeled secondary antibody for 30 minutes at room temperature. Sections were then treated with the avidin-peroxidase-labeled biotin complex (ABC, Vector Labs, Foster City, CA) and visualized by treating with either 33-diaminobenzidine-4-HCL (DAB) $/ \mathrm{H}_{2} \mathrm{O}_{2}$ (Biomeda, Foster City, CA) or NovaRed (Vector Labs, Foster City, CA, Cat. number SK-4800). Sections were then lightly counterstained with hematoxylin, dehydrated through increasing concentrations of ethanol, cleared in xylene, and mounted in Permount. Specimens were examined and photographed with a Nikon FXA microscope, and digital images were recorded using a Nikon DXM1200F digital camera and processed using Image Pro Plus (Phase 3 Imaging, Glen Mills, PA).

2.7. Quantitation and Statistics. Leaky and nonleaky vessels, GFAP-positive and GFAP-negative astrocytes, and vimentinpositive and vimentin-negative neurons were imaged in sections of $\mathrm{MBO}$ culture slices. Images were optimized and counting was performed using the counting feature of Adobe Photoshop. Three sections were examined per treatment group, with at least ten viewing fields counted from each section, for a total of 30 viewing fields per treatment group. Only blood vessels with endothelial cell nuclei, astrocytes with their nuclei, and neurons with their nuclei within the plane of section were included in the count. Blood vessels were considered leaky if they showed a gradient of immunostaining surrounding the vessel. Astrocytes were considered GFAP-positive if they showed staining within their cell body and dendrites. Neurons were considered vimentin-positive if they showed immunostaining in the cell body and/or main apical dendrite. The percentage of total leaky vessels, GFAP-positive astrocytes, and vimentin-positive neurons for histamine treated and control slices were plotted. Mean \pm SEM was used to represent the variations within each group. A two-tailed Student's $t$-test or one-way ANOVA was performed to determine the statistical significance. ${ }^{*} P<$ $0.05 ;{ }^{* *} P<0.01 ;{ }^{* * *} P<0.001$.

\section{Results}

While the use of MBO cultures to study the brain's response to specific treatments and/or conditions is well-documented $[26,40,41,48]$, there is no information on the integrity of the blood vessels in $\mathrm{MBO}$ cultures, a critical determinant in these experiments. To fill this gap, MBO slice cultures were generated and treated with or without histamine as described in Section 2. To further verify the successful penetrance of histamine, $2 \mathrm{~mm}$ slices were sectioned and grouped at different depths from the slice surface (proximal, 0-350 $\mu \mathrm{m}$; middle, $350-700 \mu \mathrm{m}$; and distal, $700-1050 \mu \mathrm{m}$ from the slice surface).

\subsection{Histamine Treatment Increases Blood Vessel Permeability} in $M B O$ Cultures. IgG localized in perivascular leak clouds emerging from a discrete region along the length of vessels have been identified as a marker for BBB breakdown [7, 49]. Conversely, perivascular leak clouds are rare and IgG is restricted to the lumen of blood vessels (BVs) under healthy status. To detect the extravasated IgG in the brain interstitium, antibodies against mouse IgG were used for immunostaining. Representative images from untreated controls (panels (a1), (a2), and (a3)) and histamine-treated samples (panels (b1), (b2), and (b3)) are presented in Figure 1. Quantification from multiple fields was also acquired and plotted in Figure 1(c).

The results demonstrate more perivascular leak clouds in the histamine-treated MBO cultures (indicated by dotted circles in Figure 1(b)) compared to the corresponding untreated controls (Figure 1(a)). In the histamine-treated $2 \mathrm{~mm}$ slices, the percentage of leaky blood vessels (BVs) increases significantly $(P<0.001)$ compared to controls (Figure $1(\mathrm{c}))$. Furthermore, the difference is significant regardless of the distance from the slice surface-proximal, middle, and distal (Figure 1(c)). An additional observation is that there is no significant difference in the percentage of leaky vessels detected among the three groups in control sections based on one-way ANOVA ( $P=0.3076)$. On the other hand, in the histamine-treated samples, the three groups show differences in the percentage of leaky BVs $(P=0.0015$, one-way ANOVA); especially, the sections distal from the slice surface exhibit significantly more leaky BVs compared to the proximal sections $(P<0.001$, two-tailed student $t$ test). These results suggest that histamine is definitely able to exert its effect through the $2 \mathrm{~mm}$ thickness. At present, it is unclear whether the difference between the proximal and distal sections is biological or technical in origin. Overall, the results above demonstrate an increase of BV permeability upon histamine treatment in the MBO cultures.

3.2. Histamine Treatment Leads to Astrocyte Activation in $M B O$ Cultures. To examine how histamine affects activation of astrocytes, changes in GFAP expression in $\mathrm{MBO}$ 


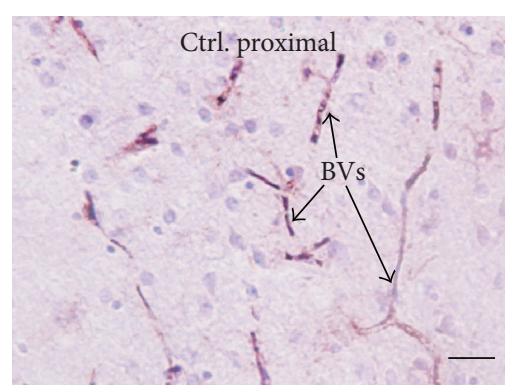

(a1)

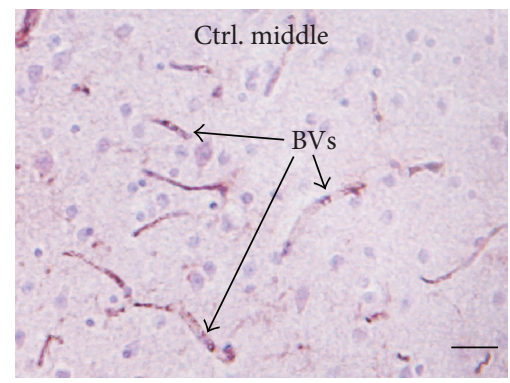

(a2)

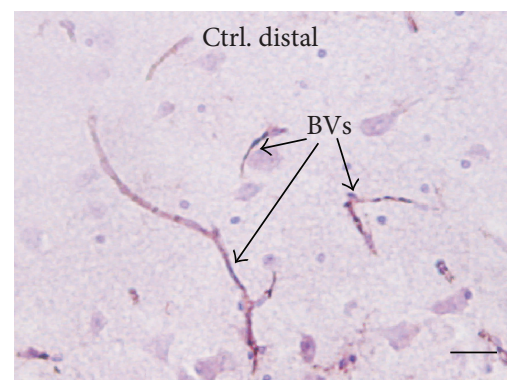

(a3)

(a)

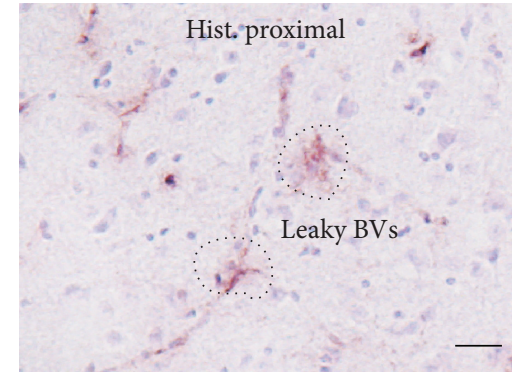

(b1)

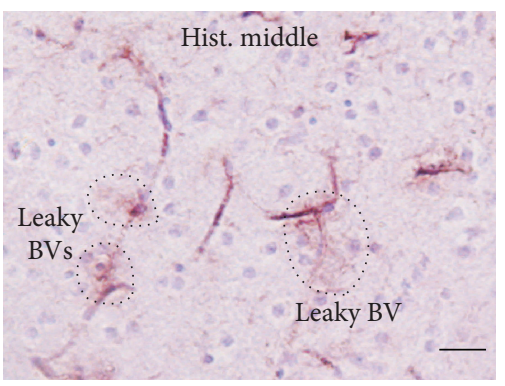

(b2)

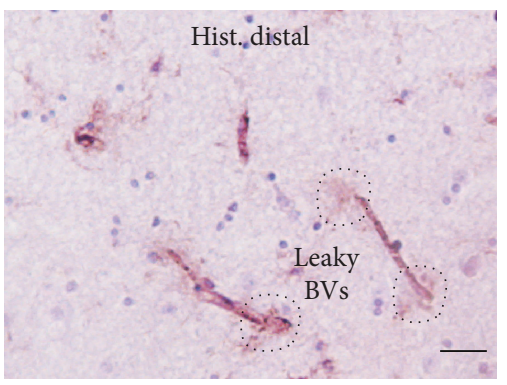

(b3)

(b)

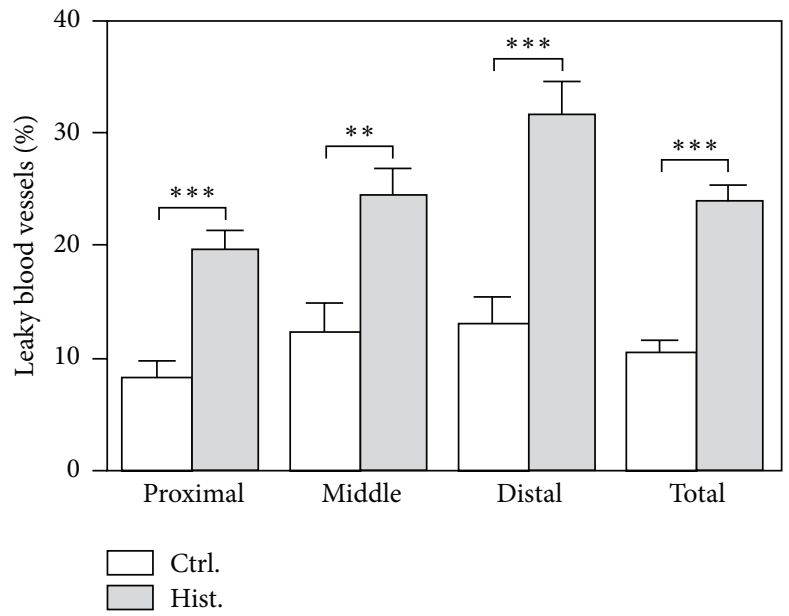

(c)

FIGURE 1: Histamine causes BBB breakdown in MBO cultures. ((a1)-(a3)) In control MBO sections, IgG (visualized by NovaRED) is mainly confined to the lumen in blood vessel (BV). Arrows indicate BVs. ((b1)-(b3)) In histamine-treated MBO sections, extravasated IgG (visualized by NovaRED) surrounding BVs is indicated by dotted circles. Sections (a1) and (b1) are from the proximal portion of the MBO tissue (0$350 \mu \mathrm{m}$ from the slice surface); sections (a2) and (b2) are from the middle portion of the MBO tissue (350-700 $\mu \mathrm{m}$ from the slice surface); and sections (a3) and (b3) are from the distal portion of the MBO tissue (700-1050 $\mu \mathrm{m}$ from the slice surface). The sections are counterstained with hematoxylin to show nucleus in purple as described in Section 2. Scale bars, $100 \mu \mathrm{m}$. (c) Quantification shows more leaky BVs in the histamine-treated $\mathrm{MBO}$ cultures compared to the controls. Leaky BVs are counted from multiple images, normalized by the total numbers of all BVs and plotted. Mean \pm SEM is used to represent the variations within each group. ${ }^{*} P<0.05 ;{ }^{* *} P<0.01 ;{ }^{* * *} P<0.001$. 


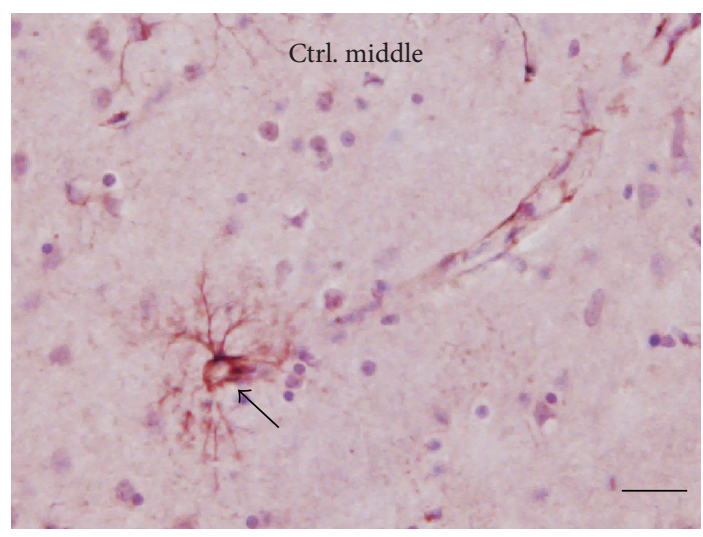

(a)

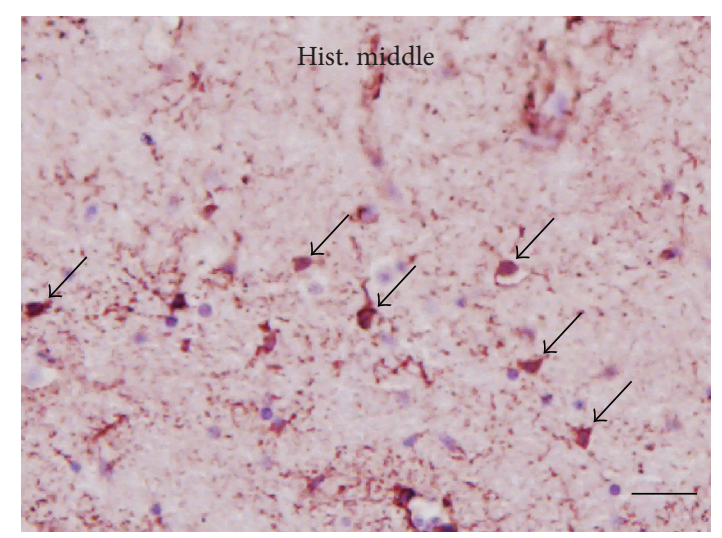

(b)

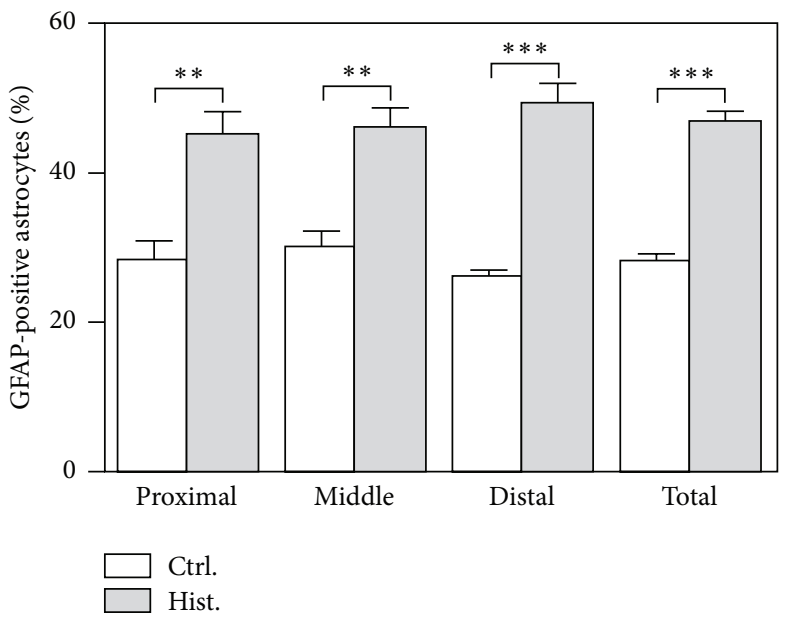

(c)

FIgURE 2: Histamine leads to astrocyte activation in MBO cultures. (a) Control MBO cultures show few astrocytes that are GFAP-positive (visualized by NovaRED and indicated by arrows). (b) Histamine-treated MBO cultures show many intensely GFAP-positive astrocytes (visualized by NovaRED and indicated by arrows). In both (a) and (b), sections are from the middle portion of the MBO tissue (350$700 \mu \mathrm{m}$ from the slice surface) and counterstained with hematoxylin to show nucleus in purple as described in Section 2. Scale bar, $100 \mu \mathrm{m}$. (c) Quantification shows more GFAP-positive astrocytes in the histamine-treated MBO cultures compared to the controls. GFAP-positive astrocytes are counted from multiple images, normalized by the total cell numbers and plotted. Mean \pm SEM is used to represent the variations within each group. ${ }^{*} P<0.05 ;{ }^{* *} P<0.01 ;{ }^{* * *} P<0.001$.

cultures were investigated by immunostaining with antiGFAP antibodies. Quantitative analyses from all three groups (proximal, middle, and distal) are presented in Figure 2, along with images from the middle sections with or without histamine treatment as an example. Compared with the control (Figure 2(a)), an increase in the number of GFAPpositive cell bodies and a more scattered distribution of GFAP are observed in the histamine-treated samples (Figure 2(b)). Quantitative analyses also reveal significantly elevated density of GFAP-positive astrocytes upon histamine treatment compared to the controls $(P<0.001$, Figure $2(\mathrm{c}))$. There is no significant difference among the three groups-proximal, middle, and distal (untreated, $P=0.5124$; treated, $P=$ 0.6343; one-way ANOVA), leading to the conclusion that the response is comparable regardless of the distance from the slice surface. Thus, the results here show that histamine treatment in $\mathrm{MBO}$ cultures elicits astrocyte responses, indicated by increased GFAP expression.
3.3. Vimentin Is Expressed in Neurons in Response to Exposure to Histamine. Under normal, nonpathological conditions, vimentin is expressed in the brain only by endothelial cells and developing neurons. Our studies show that neurons can undergo a localized damage-response that includes the expression of vimentin to reestablish their dendritic trees [26]. In order to test if histamine treatment elicits similar responses from neurons in $\mathrm{MBO}$ slice cultures, immunostaining with antibodies specific for vimentin was performed on histological sections of MBO cultures with and without histamine treatment. As shown in Figure 3, histamine treatment is accompanied by increased density of neurons expressing vimentin (indicated by red arrows, Figure 3(b) versus Figure 3(a)) while vimentin expression is generally restricted to vascular endothelial cells in untreated samples. It is also noteworthy that staining for vimentin is much weaker in the vimentin-positive neurons from the controls compared to those from histamine treated sections. Images 


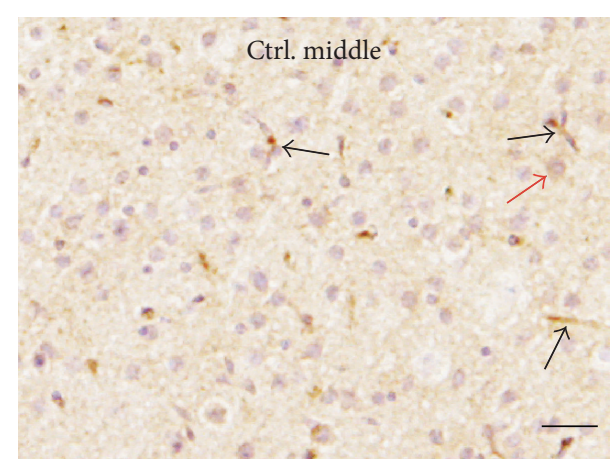

(a)

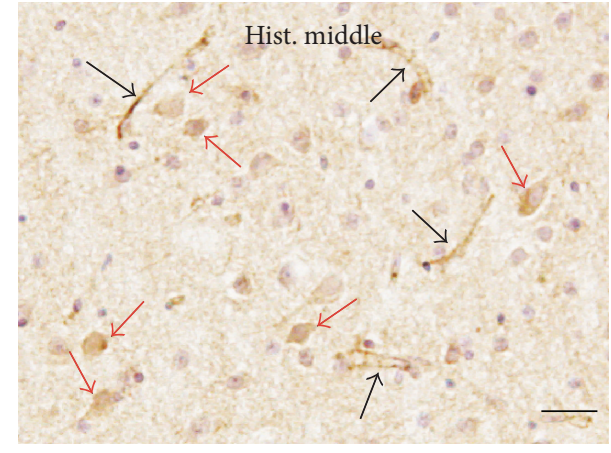

(b)

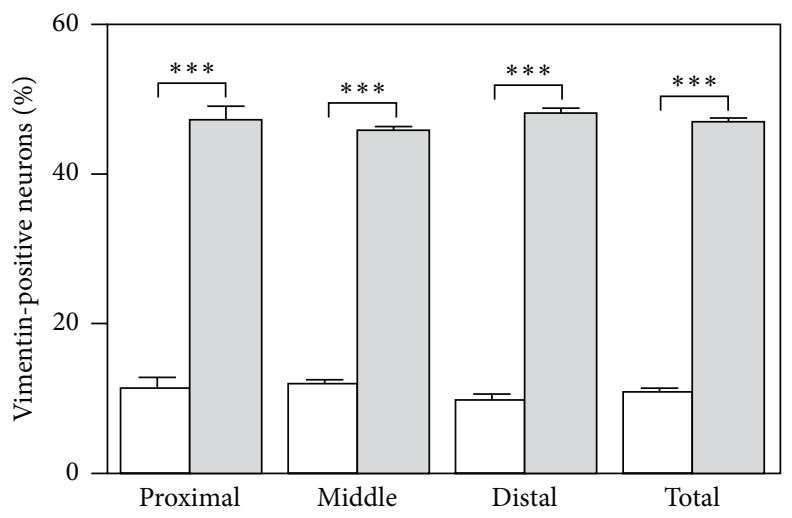

Ctrl. Hist.

(c)

FIGURE 3: Histamine leads to neuronal damage and a concurrent damage response in MBO cultures. (a) In control MBO cultures, vimentin expression (visualized by DAB in brown) is found in BVs (indicated by black arrows) and very few neurons at a low level (indicated by red arrows). (b) In the histamine-treated MBO cultures, vimentin (visualized by DAB in brown) is localized in the neurons (indicated by red arrows) as well as BVs (indicated by black arrows). In both (a) and (b), sections are from the middle portion of the MBO tissue (350-700 $\mu \mathrm{m}$ from the slice surface) and counterstained with hematoxylin to show nucleus in purple as described in Section 2. Scale bar, $100 \mu \mathrm{m}$. (c) Quantification shows more vimentin-positive neurons in the histamine-treated MBO cultures compared to the controls. Vimentin-positive neurons are counted from multiple images, normalized by the total cell numbers, and plotted. Mean \pm SEM is used to represent the variations within each group. ${ }^{*} P<0.05 ;{ }^{* *} P<0.01 ;{ }^{* * *} P<0.001$.

from these samples were quantitated and the result is plotted in Figure 3(c). Similar to GFAP, the source of the sections (proximal, middle, or distal) does not make a difference in the density of vimentin-positive neurons (untreated, $P=0.5495$; treated, $P=0.5815$; one-way ANOVA). However, compared to those untreated controls, a greater than fourfold increase is detected in the histamine-treated samples (Figure 3(c)). This conclusion holds true regardless of the proportion of the slices in the MBO cultures. Thus, we conclude that histamine treatment produces neuronal responses as measured by increased vimentin in MBO slice cultures (Figure 3).

\subsection{Histamine Induced Changes in MBO Cultures Are Inde-} pendent of the Slice's Thickness and Resemble the Pathology in $A D$ Patients. In order to determine if the thickness of the slices had a significant influence on the results, slices with $1 \mathrm{~mm}$ thickness were generated and used in the same experimental setting. The results are plotted in Figure 4(a).
As a comparison, the results with $2 \mathrm{~mm}$ thickness are also presented (Figure 4(b)). The changes are comparable between the $1 \mathrm{~mm}$ slices and $2 \mathrm{~mm}$ ones among the three parameters tested. As described previously, overall the $2 \mathrm{~mm} \mathrm{MBO}$ cultures display an increased BV leakage $[(23.87 \pm 1.46) \%$, histamine-treated versus $(10.38 \pm 1.16) \%$, control], elevated astrocyte activation $[(46.51 \pm 1.75) \%$, histamine-treated versus $(27.83 \pm 1.32) \%$, control], and a severe neuronal damageresponse [( $46.66 \pm 0.87) \%$, histamine-treated versus $(10.59 \pm$ $0.79) \%$, control]. Within the $1 \mathrm{~mm} \mathrm{MBO}$ cultures, similar effects are perceived, where $(47.66 \pm 1.64) \%$ of GFAP-positive astrocytes are detected in the histamine-treated samples while only $(25.54 \pm 1.00) \%$ are detected in the control; (50.68 $\pm 1.09) \%$ of neurons display vimentin in the treated ones compared to $(12.55 \pm 0.41) \%$ in the control; and the BV leakage increases from $(15.49 \pm 2.26) \%$ to $(32.00 \pm 3.15) \%$ upon histamine treatment. In general, there is about a twofold increase in percentage of leaky BVs and activated astrocytes, 


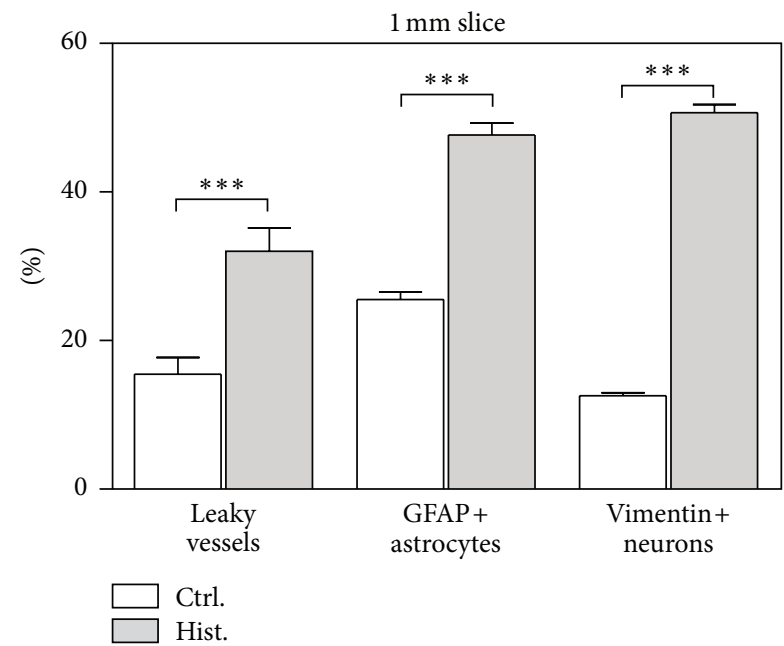

(a)

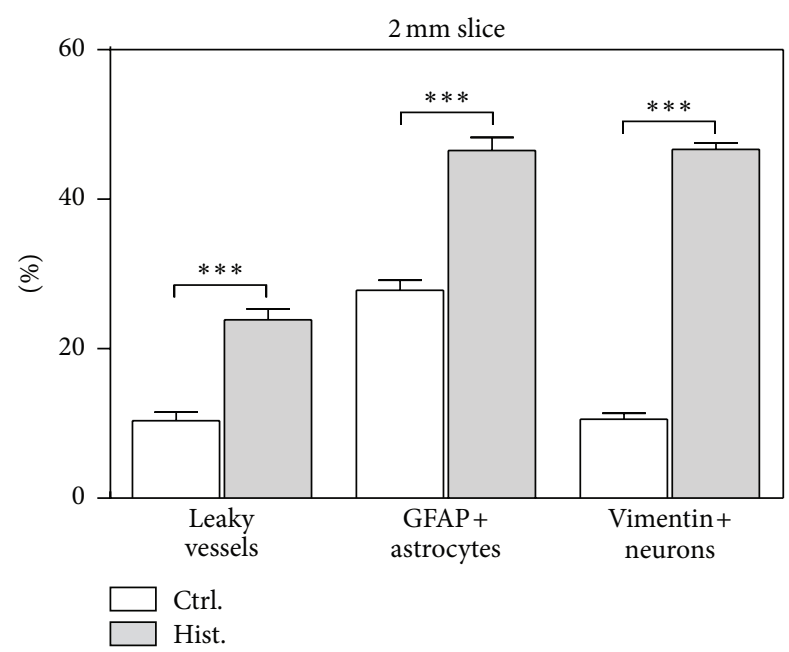

(b)

FIGURE 4: Histamine is able to induce pathological changes in MBO cultures, regardless of their thickness. Treatment of both $1 \mathrm{~mm}$ (a) and $2 \mathrm{~mm}$ (b) thick MBO cultures with histamine leads to an increase in blood vessel leakage, astrocyte activation, and neuronal damage responses, compared to controls. Mean \pm SEM is used to represent the variations within each group. ${ }^{*} P<0.05 ;{ }^{* *} P<0.01 ;{ }^{* * *} P<0.001$.

while there is a fourfold increase in the vimentin-positive neurons, irrespective of the slice thickness when the MBO slices are treated with histamine.

To compare the pathological changes in $\mathrm{MBO}$ cultures with those in $\mathrm{AD}$ patients, immunohistochemistry for IgG, GFAP, and vimentin was also performed of human brain sections. The representative images from sections from $A D$ patients (panels B, D, and F in Supplementary Figure 1 in Supplementary Material available online at http://dx.doi.org/ $10.1155 / 2015 / 937148$ ) as well as age-matched, neurologically normal brains that served as controls (panels $\mathrm{A}, \mathrm{C}$, and $\mathrm{E}$ in Figure $\mathrm{S} 1$ ) are presented. Breaches in $\mathrm{BBB}$ indicated by the efflux of IgG, astrocyte activation marked by increased GFAP expression, and a neuronal damage-response highlighted by increased vimentin expression are all observed. These observations are consistent with previous reports $[7,26]$ and most importantly validate the use of the MBO culture system in investigating $\mathrm{AD}$.

\section{Discussion}

The results presented above demonstrate that in vitro histamine treatment of $\mathrm{MBO}$ cultures can induce $\mathrm{BBB}$ breaches (Figure 1), astrocyte activation (Figure 2), and neuronal damage response (Figure 3), all of which are observed in $\mathrm{AD}$ patients (Figure S1). These results also lead to the conclusion that histamine is able to permeate the brain interstitium within a short time and this effect is not influenced by the thickness of the slice tested (Figure 4).

Histamine is known to bind to four different receptors: H1R, H2R, H3R, and H4R. These histamine receptors are known to interact with different $G$ proteins and, subsequently, activate different signaling cascades (Figure 5). However, one common thread among these is through calcium $\left(\mathrm{Ca}^{2+}\right)$. To arrive at possible mechanisms by which histamine exerts

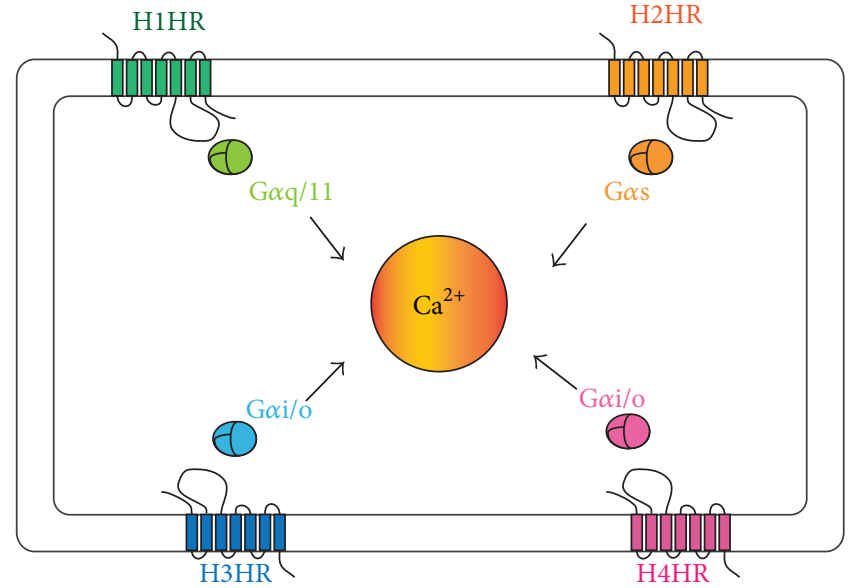

FIGURE 5: Histamine signaling through different receptor types converges at cellular calcium levels. The four major types of histamine receptors interact with different $\mathrm{G} \alpha$ proteins as indicated. The subsequent steps in the signaling pathway are variable. However, one common feature is that they all affect cellular calcium levels.

its effects on the MBO culture system, the implications of current knowledge in each of the three major cell-types involved in this study-endothelial cells, glial cells, and neurons-are discussed below.

4.1. Histamine and $B B B$ Breakdown: $H 2 R$ on Endothelial Cells? BBB breakdown is an important pathology commonly associated with $\mathrm{AD}$, as it allows for the extravasation of potentially damaging humoral elements such as autoimmune antibodies, complement components, $\mathrm{A} \beta 42$, and proinflammatory mediators $[7,50-52]$. It has also been shown that, in dynamic systems, histamine stresses the tight junctions between adjacent endothelial cells via histamine receptors, 
TABLE 1: Multiple histamine receptor types are expressed in relevant cells and all affect BBB permeability.

\begin{tabular}{lll}
\hline Histamine receptor type & Expression in the cells relevant to the study & Effect on BBB permeability \\
\hline H1R & $\begin{array}{l}\text { Neurons [88-90], astrocytes [72, 91-93], endothelial } \\
\text { cells [56, 57] }\end{array}$ & H1R signaling reduces BBB permeability [58] \\
\hline H2R & Neurons [94], astrocytes [91, 92], endothelial cells [95] & H2R signaling increases BBB permeability [49] \\
\hline H3R & $\begin{array}{l}\text { Neurons [90, 96], astrocytes [92, 97], endothelial cells } \\
{[56]}\end{array}$ & $\begin{array}{l}\text { H3R knockout mice show greater BBB } \\
\text { permeability compared to WT mice [59, 60] }\end{array}$ \\
\hline H4R & Neurons? [98], endothelial cells [56, 98] & $\begin{array}{l}\text { H4R knockout mice show greater BBB } \\
\text { permeability compared to WT mice [59, 60] }\end{array}$ \\
\hline
\end{tabular}

The current knowledge on the expression of the histamine receptors in the three major cell-types relevant to the current study as well as the effect on BBB permeability is summarized. The citations are also provided.

creating intercellular space that allows for the leakage of humeral elements into the surrounding parenchyma [53-55]. All of the four histamine receptors, H1R, H2R, H3R, and $\mathrm{H} 4 \mathrm{R}$, have been reported to be expressed on brain endothelial cells and playing critical roles in regulating $\mathrm{BBB}$ permeability (Table 1) [56, 57]. H1R signaling reduces BBB permeability [58], while $\mathrm{H} 2 \mathrm{R}$ signaling elevates $\mathrm{Ca}^{2+}$ level and leads to increased $\mathrm{BBB}$ permeability [49]. The knockout mice for both $\mathrm{H} 3 \mathrm{R}$ and $\mathrm{H} 4 \mathrm{R}$ show greater $\mathrm{BBB}$ permeability compared to WT mice $[59,60]$. In our current study with $\mathrm{MBO}$ cultures, we demonstrate that histamine increases the $\mathrm{BBB}$ permeability leading to extravasation of serum components as indicated by IgG leakage. Since that effect is associated with the $\mathrm{H} 2 \mathrm{R}$ and $\mathrm{H} 2 \mathrm{R}$ is expressed in endothelial cells, we propose that histamine, most likely, acts through H2R on the endothelial cells.

Histamine has been previously shown to cause significant increases in intracellular $\mathrm{Ca}^{2+}$ in endothelial cells $[61,62]$. This elevated $\mathrm{Ca}^{2+}$ level causes cellular contraction and finally leads to an increase in the permeability of the BBB [16]. On the other hand, $\mathrm{Ca}^{2+}$ dysregulation also plays an important role in AD pathology, where it may lead to a variety of changes including cellular loss $[63,64]$. Alteration in $\mathrm{Ca}^{2+}$ regulation has been reported in multiple mouse models of $\mathrm{AD}[63,65]$. Further experimental investigation is in progress to evaluate the role of $\mathrm{H} 2 \mathrm{R}$ and determine if the mechanism of action on endothelial cells involves $\mathrm{Ca}^{2+}$.

\subsection{Histamine-Induced Gliosis: Indicator of Inflammatory} Damage in $M B O$ Cultures. Inflammation within the brain parenchyma contributes significantly to $\mathrm{AD}$ pathogenesis (see [6] for an extensive review). An established and accepted marker of such inflammation is astrocyte activation, also known as gliosis, and observed through upregulation of GFAP [66]. Activated astrocytes are evident in the brain from transgenic animal models of $\mathrm{AD}[6,67]$ as well as in the regions surrounding amyloid plaques from the $\mathrm{AD}$ patients $[68,69]$. In the present study, we show that histamine is able to increase gliosis in MBO cultures by almost twofold.

Three of the four histamine receptors-H1R, H2R, and $\mathrm{H} 3 \mathrm{R}$ - are all expressed in astrocytes, but no H4R has been reported (Table 1). A strong correlation between increase in the H3R, GFAP, and vimentin mRNA levels has been reported in postmortem AD brains [70]. Previous literature also demonstrates that H1Rs expressed on astrocytes regulate cytoplasmic $\mathrm{Ca}^{2+}$ via PKC-MAPK signaling pathway [71-73]. Therefore, the observed increase in GFAP expression here may be caused by a direct interaction between histamine and astrocytes via more than one receptor. It is conceivable that the effect may not be mediated by histamine receptors on the astrocytes. Since it is known that astrocytes respond to $\mathrm{BBB}$ breakdown by a swelling of their foot processes $[38,39]$, the possibility that the $\mathrm{BBB}$ breach induced by histamine causes the increase in astrocytic GFAP cannot be ruled out. In either case, histamine is responsible for the increased gliosis in the $\mathrm{MBO}$ cultures that resemble $\mathrm{AD}$. Therefore, gliosis, a pathological change downstream to BBB breakdown, is effectively observable in the $\mathrm{MBO}$ cultures, attesting the power of the $\mathrm{MBO}$ system in recapitulating pathologies seen in $\mathrm{AD}$ patients and also in exploring the potential mechanisms underlying it.

4.3. Histamine and Neuron Damage Response: Primary or Secondary? Vimentin is an intermediate filament protein that is important for neuronal growth/development and is necessary for the extension and branching of neurites [74]. Thus, it is commonly expressed by neuronal precursor cells in the developing CNS of both rodents and humans [24, 26, 75]. In the healthy, adult brain, vimentin expression is mainly restricted to endothelial cells $[24,74,76,77]$. However, in the AD brain, vimentin has been found within neurofibrillary tangles, a pathological hallmark associated with the disease [78, 79]. Moreover, we have shown that vimentin is expressed by neurons in $\mathrm{AD}$ brains, possibly as part of a damage-response mechanism in order to reestablish their dendritic trees [26].

In our present study, histamine administration results in perinuclear vimentin expression within the cell bodies of neurons, whereas it is mainly restricted to the vascular epithelium of control MBO cultures. Neurons throughout the brain express histamine receptors, H1R, H2R, and H3R; however, there is no consensus on H4R (Table 1). Therefore, it is possible that histamine directly binds to neurons in $\mathrm{MBO}$ cultures, causing localized damage due to excitotoxicity and inducing the neuron's damage-response, including expression of vimentin. Increase in the H3R and vimentin has been reported in postmortem $\mathrm{AD}$ brains [70]. Further experiments are under investigation to determine the subtypes of histamine receptors on the responding neurons in 
the $\mathrm{MBO}$ cultures. Alternatively, the activation of vimentin expression could be secondary to the BBB breakdown caused by histamine, which could allow plasma components, such as brain-reactive autoantibodies, complement components, and $\mathrm{A} \beta 42$, to directly bind to and damage the $\mathrm{MBO}$ neurons, as has been shown in $\mathrm{AD}$ brains [7, 21-23]. Histamine's ability to elicit the neuronal response within such a short time period in $\mathrm{MBO}$ cultures shows the immediacy of the neuronal damage-response mechanism. Within the relatively brief 1 hour of histamine exposure in this study, neurons already begin to repair themselves and reestablish their lost connections so that they can continue to function normally. Moreover, the fact that so many neurons display a damage response in the present study indicates the overall extent to which histamine can mediate damage in the brain. For those reasons, it suggests that the $\mathrm{MBO}$ cultures have a significant potential to investigate neuronal repair mechanisms.

4.4. Histamine and AD. We have shown histamine to be a powerful molecule in terms of its abilities to create pathological changes in $\mathrm{MBO}$ cultures that are consistent with those found in AD. This is in line with its proinflammatory nature. Interestingly, it has been previously noted that the use of anti-inflammatory drugs has benefits in treating the cognitive symptoms of $\mathrm{AD}$ [80-86]. Yet, the merits of utilizing antihistamines as a treatment may largely depend on the timing of administrations since the cellular changes found in $\mathrm{AD}$ have been shown to predate the symptomology by years to decades [87].

It is entirely possible that histamine-induced inflammation is an early and/or downstream contributor in AD. After all, histamine is capable of creating several pathologies consistent with the disease process and triggering a cascade of problems. As shown in the present paper, histamine can cause the BBB breakdown that allows $A \beta 42$ and other humoral element access to cells of the brain. Once histamine enters the brain parenchyma, it could potentate these adverse effects by damaging neurons, thus resulting in increases in gliosis.

Cells in $\mathrm{MBO}$ cultures are not only capable of being damaged by histamine, but also responding to that damage; that is, astrocytes respond to inflammatory damage by undergoing gliosis and neurons respond to damage by upregulating vimentin production. As such, our histamine-treated $\mathrm{MBO}$ model system provides a useful model to not only study the effects of inflammatory damage as seen in $\mathrm{AD}$, but also to study the way in which the brain responds to this damage. In conclusion, our current study indicates that MBO cultures treated with histamine are a quick, simple, and effective tool for investigating pathological changes, some of which are demonstrably associated with AD.

\section{Conclusions}

In the present study we show that when administered in $\mathrm{MBO}$ cultures, histamine is able to induce $\mathrm{BBB}$ breaches and cellular pathologies that were observed in AD. Results suggest that histamine is a potent mediator of BBB breakdown, astrocyte activation, and neuronal damage response. Therefore, we propose that $\mathrm{MBO}$ cultures treated with histamine can provide a quick and powerful model system to study the cellular pathologies associated with $\mathrm{AD}$ and to test potential medications to reverse or mitigate these pathological changes.

\section{Conflict of Interests}

The authors declare that there is no conflict of interests regarding the publication of this paper.

\section{Authors' Contribution}

Jonathan C. Sedeyn and Hao Wu are with equal contributions.

\section{Acknowledgments}

The work was supported by grants from the New Jersey Health (previously UMDNJ) Foundation and the Osteopathic Heritage Foundation. The support by the RowanSOM Graduate School of Biomedical Sciences is gratefully acknowledged.

\section{References}

[1] H. W. Querfurth and F. M. LaFerla, "Alzheimer's disease," The New England Journal of Medicine, vol. 362, no. 4, pp. 329-344, 2010.

[2] Alzheimer's Association, "2015 Alzheimer's disease facts and figures," Alzheimer's \& Dementia, vol. 11, no. 3, p. 332, 2015.

[3] H. Braak and E. Braak, "Neuropathological stageing of Alzheimer-related changes," Acta Neuropathologica, vol. 82, no. 4, pp. 239-259, 1991.

[4] O. Felician and T. A. Sandson, "The neurobiology and pharmacotherapy of Alzheimer's disease," Journal of Neuropsychiatry and Clinical Neurosciences, vol. 11, no. 1, pp. 19-31, 1999.

[5] S. Sanders and C. Morano, "Alzheimer's disease and related dementias," Journal of Gerontological Social Work, vol. 50, supplement 1, pp. 191-214, 2008.

[6] H. Akiyama, T. Arai, H. Kondo, E. Tanno, C. Haga, and K. Ikeda, "Cell mediators of inflammation in the Alzheimer disease brain," Alzheimer Disease \& Associated Disorders, vol. 14, no. 1, pp. S47-S53, 2000.

[7] P. M. Clifford, S. Zarrabi, G. Siu et al., "A $\beta$ peptides can enter the brain through a defective blood-brain barrier and bind selectively to neurons," Brain Research, vol. 1142, no. 1, pp. 223236, 2007.

[8] P. M. Clifford, G. Siu, M. Kosciuk et al., " $\alpha 7$ nicotinic acetylcholine receptor expression by vascular smooth muscle cells facilitates the deposition of $\mathrm{A} \beta$ peptides and promotes cerebrovascular amyloid angiopathy," Brain Research, vol. 1234, pp. 158-171, 2008.

[9] D. W. Dickson, "Neuropathological diagnosis of Alzheimer's disease: a perspective from longitudinal clinicopathological studies," Neurobiology of Aging, vol. 18, no. 4, supplement, pp. S21-S26, 1997.

[10] G. G. Glenner and C. W. Wong, "Alzheimer's disease: initial report of the purification and characterization of a novel cerebrovascular amyloid protein," Biochemical and Biophysical Research Communications, vol. 120, no. 3, pp. 885-890, 1984. 
[11] J. T. Rogers, A. I. Bush, H.-H. Cho et al., "Iron and the translation of the amyloid precursor protein (APP) and ferritin mRNAs: riboregulation against neural oxidative damage in Alzheimer's disease," Biochemical Society Transactions, vol. 36, no. 6, pp. 1282-1287, 2008.

[12] D. J. Selkoe, "Developing preventive therapies for chronic diseases: lessons learned from Alzheimer's disease," Nutrition Reviews, vol. 65, supplement 3, pp. S239-S243, 2007.

[13] B. V. Zlokovic, "New therapeutic targets in the neurovascular pathway in Alzheimer's disease," Neurotherapeutics, vol. 5, no. 3, pp. 409-414, 2008.

[14] R. G. Nagele, P. M. Clifford, G. Siu et al., "Brain-reactive autoantibodies prevalent in human sera increase intraneuronal amyloid- $\beta_{1-24}$ deposition," Journal of Alzheimer's Disease, vol. 25, no. 4, pp. 605-622, 2011.

[15] G. W. Goldstein, "Endothelial cell-astrocyte interactions. A cellular model of the blood-brain barrier," Annals of the New York Academy of Sciences, vol. 529, no. 1, pp. 31-39, 1988.

[16] W. G. Mayhan, "Regulation of blood-brain barrier permeability," Microcirculation, vol. 8, no. 2, pp. 89-104, 2001.

[17] M. W. B. Bradbury, "The structure and function of the bloodbrain barrier," Federation Proceedings, vol. 43, no. 2, pp. 186-190, 1984.

[18] R. D. Bell and B. V. Zlokovic, "Neurovascular mechanisms and blood-brain barrier disorder in Alzheimer's disease," Acta Neuropathologica, vol. 118, no. 1, pp. 103-113, 2009.

[19] P. Grammas, "Neurovascular dysfunction, inflammation and endothelial activation: implications for the pathogenesis of Alzheimer's disease," Journal of Neuroinflammation, vol. 8, no. 3, article 26, 2011.

[20] E. C. Levin, N. K. Acharya, M. Han et al., "Brain-reactive autoantibodies are nearly ubiquitous in human sera and may be linked to pathology in the context of blood-brain barrier breakdown," Brain Research, vol. 1345, pp. 221-232, 2010.

[21] C. Bouras, B. M. Riederer, E. Kövari, P. R. Hof, and P. Giannakopoulos, "Humoral immunity in brain aging and Alzheimer's disease," Brain Research Reviews, vol. 48, no. 3, pp. 477-487, 2005.

[22] M. R. D’Andrea, "Evidence linking neuronal cell death to autoimmunity in Alzheimer's disease," Brain Research, vol. 982, no. 1, pp. 19-30, 2003.

[23] T. D. Stein, J. P. Fedynyshyn, and R. E. Kalil, "Circulating autoantibodies recognize and bind dying neurons following injury to the brain," Journal of Neuropathology \& Experimental Neurology, vol. 61, no. 12, pp. 1100-1108, 2002.

[24] P. Cochard and D. Paulin, "Initial expression of neurofilaments and vimentin in the central and peripheral nervous system of the mouse embryo in vivo," The Journal of Neuroscience, vol. 4, no. 8, pp. 2080-2094, 1984.

[25] W. W. Franke, C. Grund, C. Kuhn, B. W. Jackson, and K. Illmensee, "Formation of cytoskeletal elements during mouse embryogenesis: III. Primary mesenchymal cells and the first appearance of vimentin filaments," Differentiation, vol. 23, no. 1-3, pp. 43-59, 1982.

[26] E. C. Levin, N. K. Acharya, J. C. Sedeyn et al., "Neuronal expression of vimentin in the Alzheimer's disease brain may be part of a generalized dendritic damage-response mechanism," Brain Research, vol. 1298, pp. 194-207, 2009.

[27] F. Muramori, K. Kobayashi, and I. Nakamura, "A quantitative study of neurofibrillary tangles, senile plaques and astrocytes in the hippocampal subdivisions and entorhinal cortex in
Alzheimer's disease, normal controls and non-Alzheimer neuropsychiatric diseases," Psychiatry and Clinical Neurosciences, vol. 52, no. 6, pp. 593-599, 1998.

[28] R. G. Nagele, J. Wegiel, V. Venkataraman, H. Imaki, K.-C. Wang, and J. Wegiel, "Contribution of glial cells to the development of amyloid plaques in Alzheimer's disease," Neurobiology of Aging, vol. 25, no. 5, pp. 663-674, 2004.

[29] W. T. Norton, D. A. Aquino, I. Hozumi, F.-C. Chiu, and C. F. Brosnan, "Quantitative aspects of reactive gliosis: a review," Neurochemical Research, vol. 17, no. 9, pp. 877-885, 1992.

[30] M. S. Repka-Ramirez and J. N. Baraniuk, "Histamine in health and disease," Clinical Allergy and Immunology, vol. 17, pp. 1-25, 2002.

[31] H. Haas and P. Panula, "The role of histamine and the tuberomamillary nucleus in the nervous system," Nature Reviews Neuroscience, vol. 4, no. 2, pp. 121-130, 2003.

[32] C. G. Cochrane, "The participation of cells in the inflammatory injury of tissue," Journal of Investigative Dermatology, vol. 64, no. 5, pp. 301-306, 1975.

[33] E. Sakurai, E. Sakurai, T. Watanabe, and K. Yanai, "Uptake of Lhistidine and histamine biosynthesis at the blood-brain barrier," Inflammation Research, vol. 58, no. 1, supplement, pp. S34-S35, 2009.

[34] A. M. Butt and H. C. Jones, "Effect of histamine and antagonists on electrical resistance across the blood-brain barrier in rat brain-surface microvessels," Brain Research, vol. 569, no. 1, pp. 100-105, 1992.

[35] W. G. Mayhan, "Role of nitric oxide in histamine-induced increases in permeability of the blood-brain barrier," Brain Research, vol. 743, no. 1-2, pp. 70-76, 1996.

[36] P. A. Revest, H. C. Jones, and N. J. Abbott, “Transendothelial electrical potential across pial vessels in anaesthetised rats: a study of ion permeability and transport at the blood-brain barrier," Brain Research, vol. 652, no. 1, pp. 76-82, 1994.

[37] L. Schilling and M. Wahl, "Opening of the blood-brain barrier during cortical superfusion with histamine," Brain Research, vol. 653, no. 1-2, pp. 289-296, 1994.

[38] E. Dux and F. Joó, "Effects of histamine on brain capillariesfine structural and immunohistochemical studies after intracarotid infusion," Experimental Brain Research, vol. 47, no. 2, pp. 252-258, 1982.

[39] P. M. Gross, G. M. Teasdale, D. I. Graham, W. J. Angerson, and A. M. Harper, "Intra-arterial histamine increases blood-brain transport in rats," The American Journal of Physiology, vol. 243, no. 2, pp. H307-H317, 1982.

[40] S. Cho, A. Wood, and M. R. Bowlby, "Brain slices as models for neurodegenerative disease and screening platforms to identify novel therapeutics," Current Neuropharmacology, vol. 5, no. 1, pp. 19-33, 2007.

[41] L. Lossi, S. Alasia, C. Salio, and A. Merighi, "Cell death and proliferation in acute slices and organotypic cultures of mammalian CNS," Progress in Neurobiology, vol. 88, no. 4, pp. 221-245, 2009.

[42] V. Venkataraman, T. Duda, S. Ravichandran, and R. K. Sharma, "Neurocalcin delta modulation of ROS-GC1, a new model of $\mathrm{Ca}^{2+}$ signaling," Biochemistry, vol. 47, no. 25, pp. 6590-6601, 2008.

[43] V. Venkataraman, T. Duda, N. Vardi, K.-W. Koch, and R. K. Sharma, "Calcium-modulated guanylate cyclase transduction machinery in the photoreceptor-bipolar synaptic region," Biochemistry, vol. 42, no. 19, pp. 5640-5648, 2003. 
[44] V. Venkataraman, R. Nagele, T. Duda, and R. K. Sharma, "Rod outer segment membrane guanylate cyclase type 1-linked stimulatory and inhibitory calcium signaling systems in the pineal gland: biochemical, molecular, and immunohistochemical evidence," Biochemistry, vol. 39, no. 20, pp. 6042-6052, 2000.

[45] B. T. Hyman and J. Q. Trojanowski, "Consensus recommendations for the postmortem diagnosis of Alzheimer disease from the National Institute on Aging and the Reagan Institute Working Group on diagnostic criteria for the neuropathological assessment of Alzheimer disease," Journal of Nneuropathology and Experimental Neurology, vol. 56, no. 10, pp. 1095-1097, 1997.

[46] M. R. D’Andrea, R. G. Nagele, H.-Y. Wang, P. A. Peterson, and D. H. S. Lee, "Evidence that neurones accumulating amyloid can undergo lysis to form amyloid plaques in Alzheimer's disease," Histopathology, vol. 38, no. 2, pp. 120-134, 2001.

[47] R. G. Nagele, M. R. D’Andrea, W. J. Anderson, and H.-Y. Wang, "Intracellular accumulation of $\beta$-amyloid $_{1-42}$ in neurons is facilitated by the $\alpha 7$ nicotinic acetylcholine receptor in Alzheimer's disease," Neuroscience, vol. 110, no. 2, pp. 199-211, 2002.

[48] T. Su, B. Paradiso, Y.-S. Long, W.-P. Liao, and M. Simonato, "Evaluation of cell damage in organotypic hippocampal slice culture from adult mouse: a potential model system to study neuroprotection," Brain Research, vol. 1385, pp. 68-76, 2011.

[49] N. J. Abbott, "Inflammatory mediators and modulation of blood-brain barrier permeability," Cellular and Molecular Neurobiology, vol. 20, no. 2, pp. 131-147, 2000.

[50] H. E. de Vries, J. Kuiper, A. G. de Boer, T. J. C. Van Berkel, and D. D. Breimer, "The blood-brain barrier in neuroinflammatory diseases," Pharmacological Reviews, vol. 49, no. 2, pp. 143-156, 1997.

[51] S. M. Fullerton, G. A. Shirman, W. J. Strittmatter, and W. D. Matthew, "Impairment of the blood-nerve and blood-brain barriers in apolipoprotein E knockout mice," Experimental Neurology, vol. 169, no. 1, pp. 13-22, 2001.

[52] T. Miyakawa, A. Shimoji, R. Kuramoto, and Y. Higuchi, “The relationship between senile plaques and cerebral blood vessels in Alzheimer's disease and senile dementia. Morphological mechanism of senile plaque production," Virchows Archiv B, vol. 40, no. 2, pp. 121-129, 1982.

[53] P. Kumar, Q. Shen, C. D. Pivetti, E. S. Lee, M. H. Wu, and S. Y. Yuan, "Molecular mechanisms of endothelial hyperpermeability: implications in inflammation," Expert Reviews in Molecular Medicine, vol. 11, article e19, 2009.

[54] G. Majno, S. M. Shea, and M. Leventhal, "Endothelial contraction induced by histamine-type mediators: an electron microscopic study," The Journal of Cell Biology, vol. 42, no. 3, pp. 647-672, 1969.

[55] V. W. M. van Hinsbergh and G. P. van Nieuw Amerongen, "Intracellular signalling involved in modulating human endothelial barrier function," Journal of Anatomy, vol. 200, no. 6, pp. 549-560, 2002.

[56] K. Karlstedt, C. Jin, and P. Panula, "Expression of histamine receptor genes Hrh3 and Hrh4 in rat brain endothelial cells," British Journal of Pharmacology, vol. 170, no. 1, pp. 58-66, 2013.

[57] L. Zhang, K. Yao, Y. Fan et al., "Carnosine protects brain microvascular endothelial cells against rotenone-induced oxidative stress injury through histamine $\mathrm{H}_{1}$ and $\mathrm{H}_{2}$ receptors in vitro," Clinical and Experimental Pharmacology and Physiology, vol. 39, no. 12, pp. 1019-1025, 2012.

[58] C. Lu, S. A. Diehl, R. Noubade et al., "Endothelial histamine $\mathrm{H}_{1}$ receptor signaling reduces blood-brain barrier permeability and susceptibility to autoimmune encephalomyelitis," Proceedings of the National Academy of Sciences of the United States of America, vol. 107, no. 44, pp. 18967-18972, 2010.

[59] C. Teuscher, M. Subramanian, R. Noubade et al., "Central histamine $\mathrm{H} 3$ receptor signaling negatively regulates susceptibility to autoimmune inflammatory disease of the CNS," Proceedings of the National Academy of Sciences of the United States of America, vol. 104, no. 24, pp. 10146-10151, 2007.

[60] R. del Rio, R. Noubade, N. Saligrama et al., "Histamine H4 receptor optimizes $\mathrm{T}$ regulatory cell frequency and facilitates anti-inflammatory responses within the central nervous system," Journal of Immunology, vol. 188, no. 2, pp. 541-547, 2012.

[61] P. Bregestovski, A. Bakhramov, S. Danilov, A. Moldobaeva, and K. Takeda, "Histamine-induced inward currents in cultured endothelial cells from human umbilical vein," British Journal of Pharmacology, vol. 95, no. 2, pp. 429-436, 1988.

[62] J. R. H. Mauban, K. Wilkinson, C. Schach, and J. X.-J. Yuan, "Histamine-mediated increases in cytosolic $\left[\mathrm{Ca}^{2+}\right]$ involve different mechanisms in human pulmonary artery smooth muscle and endothelial cells," American Journal of Physiology: Cell Physiology, vol. 290, no. 2, pp. C325-C336, 2006.

[63] K. Green, I. Smith, and F. Laferla, "Role of calcium in the pathogenesis of Alzheimer's disease and transgenic models," in Calcium Signalling and Disease, pp. 507-521, Springer, Berlin, Germany, 2007.

[64] C. Supnet and I. Bezprozvanny, "The dysregulation of intracellular calcium in Alzheimer disease," Cell Calcium, vol. 47, no. 2, pp. 183-189, 2010.

[65] K. V. Kuchibhotla, S. T. Goldman, C. R. Lattarulo, H.-Y. Wu, B. T. Hyman, and B. J. Bacskai, "A $\beta$ plaques lead to aberrant regulation of calcium homeostasis in vivo resulting in structural and functional disruption of neuronal networks," Neuron, vol. 59, no. 2, pp. 214-225, 2008.

[66] H. Akiyama, S. Barger, S. Barnum et al., "Inflammation and Alzheimer's disease," Neurobiology of Aging, vol. 21, no. 3, pp. 383-421, 2000.

[67] C. Duyckaerts, M.-C. Potier, and B. Delatour, "Alzheimer disease models and human neuropathology: similarities and differences," Acta Neuropathologica, vol. 115, no. 1, pp. 5-38, 2008.

[68] S. Kumar-Singh, P. Cras, R. Wang et al., "Dense-core senile plaques in the Flemish variant of Alzheimer's disease are vasocentric," The American Journal of Pathology, vol. 161, no. 2, pp. 507-520, 2002.

[69] D. Pirici, L. Mogoanta, O. Margaritescu, I. Pirici, V. Tudorica, and M. Coconu, "Fractal analysis of astrocytes in stroke and dementia," Romanian Journal of Morphology and Embryology, vol. 50, no. 3, pp. 381-390, 2008.

[70] L. Shan, K. Bossers, U. Unmehopa, A.-M. Bao, and D. F. Swaab, "Alterations in the histaminergic system in Alzheimer's disease: a postmortem study," Neurobiology of Aging, vol. 33, no. 11, pp. 2585-2598, 2012.

[71] M. J. Lucherini and E. Gruenstein, "Histamine H1 receptors in UC-11MG astrocytes and their regulation of cytoplasmic $\mathrm{Ca}^{2+}$," Brain Research, vol. 592, no. 1-2, pp. 193-201, 1992.

[72] K. Aleš, B. Wraber, and M. Lipnik-Štangelj, “The synergistic effect of histamine and IL- 6 on NGF secretion from cultured astrocytes is evoked by histamine stimulation of IL- 6 secretion via H1-receptor-PKC-MAPK signalling pathway," Inflammation Research, vol. 57, supplement 1, pp. S33-S34, 2008.

[73] M. Lipnik-Štangelj and M. Čarman-Kržan, "The influence of histamine H1-, H2- and H3-receptor antagonists on histamine 
stimulated NGF release from cultured astrocytes," Inflammation Research, vol. 50, supplement 2, pp. S84-S85, 2001.

[74] L. J. Boyne, I. Fischer, and T. B. Shea, "Role of vimentin in early stages of neuritogenesis in cultured hippocampal neurons," International Journal of Developmental Neuroscience, vol. 14, no. 6, pp. 739-748, 1996.

[75] A. Bignami, G. Cella, and N. H. Chi, "Plasminogen activators in rat neural tissues during development and in Wallerian degeneration," Acta Neuropathologica, vol. 58, no. 3, pp. 224228, 1982.

[76] A. Bignami, T. Raju, and D. Dahl, "Localization of vimentin, the nonspecific intermediate filament protein, in embryonal glia and in early differentiating neurons. In vivo and in vitro immunofluorescence study of the rat embryo with vimentin and neurofilament antisera," Developmental Biology, vol. 91, no. 2, pp. 286-295, 1982.

[77] W. W. Franke, E. Schmid, D. L. Schiller et al., "Differentiationrelated patterns of expression of proteins of intermediate-size filaments in tissues and cultured cells," Cold Spring Harbor Symposia on Quantitative Biology, vol. 46, no. 1, pp. 431-453, 1982.

[78] D. Dahl, D. J. Selkoe, R. T. Pero, and A. Bignami, "Immunostaining of neurofibrillary tangles in Alzheimer's senile dementia with a neurofilament antiserum," Journal of Neuroscience, vol. 2, no. 1, pp. 113-119, 1982.

[79] S. H. Yen, F. Gaskin, and S. M. Fu, "Neurofibrillary tangles in senile dementia of the Alzheimer type share an antigenic determinant with intermediate filaments of the vimentin class," The American Journal of Pathology, vol. 113, no. 3, pp. 373-381, 1983.

[80] J. C. Anthony, J. C. S. Breitner, P. P. Zandi et al., "Reduced prevalence of $\mathrm{AD}$ in users of NSAIDS and $\mathrm{H} 2$ receptor antagonists: the Cache County study," Neurology, vol. 54, no. 11, pp. 20662071, 2000.

[81] C. M. Beard, S. C. Waring, P. C. O’Brien, L. T. Kurland, and E. Kokmen, "Nonsteroidal anti-inflammatory drug use and Alzheimer's disease: a case-control study in Rochester, Minnesota, 1980 through 1984," in Mayo Clinic Proceedings, Elsevier, 1998.

[82] J. C. S. Breitner, K. A. Welsh, M. J. Helms et al., "Delayed onset of Alzheimer's disease with nonsteroidal anti-inflammatory and histamine H2 blocking drugs," Neurobiology of Aging, vol. 16, no. 4, pp. 523-530, 1995.

[83] B. A. In 'T Veld, A. Ruitenberg, A. Hofman et al., "Nonsteroidal antiinflammatory drugs and the risk of Alzheimer's disease," The New England Journal of Medicine, vol. 345, no. 21, pp. 15151521, 2001.

[84] P. L. McGeer, M. Schulzer, and E. G. McGeer, "Arthritis and anti-inflammatory agents as possible protective factors for Alzheimer's disease: a review of 17 epidemiologic studies," Neurology, vol. 47, no. 2, pp. 425-432, 1996.

[85] J. Rogers, L. Kirby, S. Hempelman et al., "Clinical trial of indomethacin in Alzheimer's disease," Neurology, vol. 43, no. 8, article 1609, 1993.

[86] C. A. Szekely, J. C. S. Breitner, A. L. Fitzpatrick et al., "NSAID use and dementia risk in the cardiovascular health study role of APOE and NSAID type," Neurology, vol. 70, no. 1, pp. 17-24, 2008.

[87] K. Blennow, M. J. de Leon, and H. Zetterberg, "Alzheimer's disease," The Lancet, vol. 368, no. 9533, pp. 387-403, 2006.

[88] T. Andoh, C. Tohda, and Y. Kuraishi, "Analysis of dissociated single neurons by simple and semi-quantitative RT-PCR (reverse transcription and polymerase chain reaction)," The Japanese Journal of Pharmacology, vol. 74, no. 1, pp. 121-123, 1997.

[89] A. Molina-Hernandez, G. Rodra-guez-Marta-nez, I. EscobedoAvila, and I. Velasco, "Histamine up-regulates fibroblast growth factor receptor 1 and increases FOXP2 neurons in cultured neural precursors by histamine type 1 receptor activation: conceivable role of histamine in neurogenesis during cortical development in vivo," Neural Development, vol. 8, no. 4, 2013.

[90] E. G. Lundius, M. Sanchez-Alavez, Y. Ghochani, J. Klaus, and I. V. Tabarean, "Histamine influences body temperature by acting at $\mathrm{H} 1$ and $\mathrm{H} 3$ receptors on distinct populations of preoptic neurons," Journal of Neuroscience, vol. 30, no. 12, pp. 4369-4381, 2010.

[91] L. Hösli, E. Hösli, U. Schneider, and W. Wiget, "Evidence for the existence of histamine H1- and H2-receptors on astrocytes of cultured rat central nervous system," Neuroscience Letters, vol. 48, no. 3, pp. 287-291, 1984.

[92] D. M. Jurič, T. Mele, and M. Čarman-Kržan, "Involvement of histaminergic receptor mechanisms in the stimulation of NT-3 synthesis in astrocytes," Neuropharmacology, vol. 60, no. 7-8, pp. 1309-1317, 2011.

[93] M. Lipnik-Štangelj and M. Čarman-Kržan, "Activation of histamine H1-receptor enhances neurotrophic factor secretion from cultured astrocytes," Inflammation Research, vol. 53, no. 6, pp. 245-252, 2004.

[94] H. L. Haas and U. M. Bucher, "Histamine H2-receptors on single central neurones," Nature, vol. 255, no. 5510, pp. 634-635, 1975.

[95] K. Karlstedt, T. Sallmén, K. S. Eriksson et al., "Lack of histamine synthesis and down-regulation of $\mathrm{H} 1$ and $\mathrm{H} 2$ receptor mRNA levels by dexamethasone in cerebral endothelial cells," Journal of Cerebral Blood Flow and Metabolism, vol. 19, no. 3, pp. 321330, 1999.

[96] S. Tritto, L. Botta, V. Zampini, G. Zucca, P. Valli, and S. Masetto, "Calyx and dimorphic neurons of mouse Scarpa's ganglion express histamine $\mathrm{H} 3$ receptors," BMC Neuroscience, vol. 10, no. 1, article 70, 2009.

[97] S.-I. Sekizawa, A. G. Bechtold, R. C. Tham et al., "Housedust mite allergen and ozone exposure decreases histamine $\mathrm{H} 3$ receptors in the brainstem respiratory nuclei," Toxicology and Applied Pharmacology, vol. 247, no. 3, pp. 204-210, 2010.

[98] E. H. Schneider and R. Seifert, "The histamine $\mathrm{H}_{4}$-receptor and the central and peripheral nervous system: a critical analysis of the literature," Neuropharmacology, 2015. 


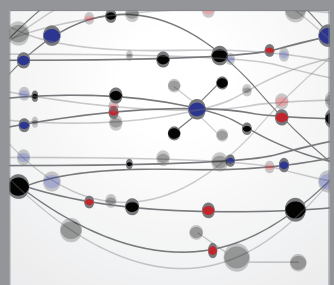

The Scientific World Journal
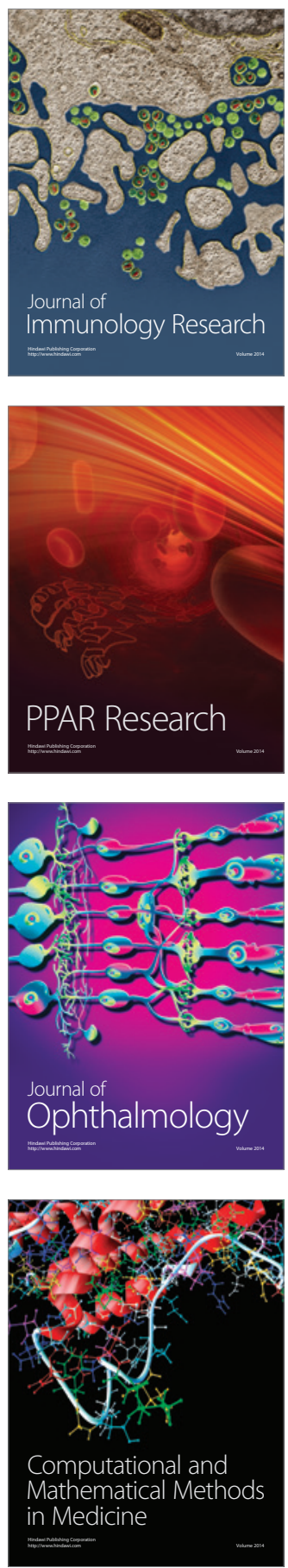

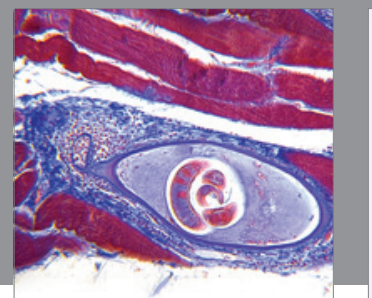

Gastroenterology

Research and Practice
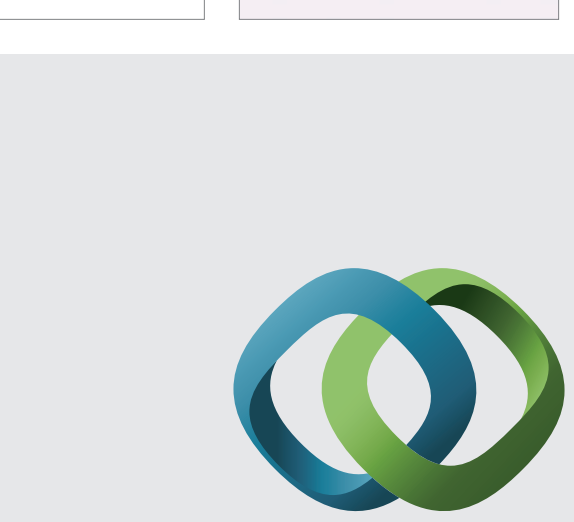

\section{Hindawi}

Submit your manuscripts at

http://www.hindawi.com
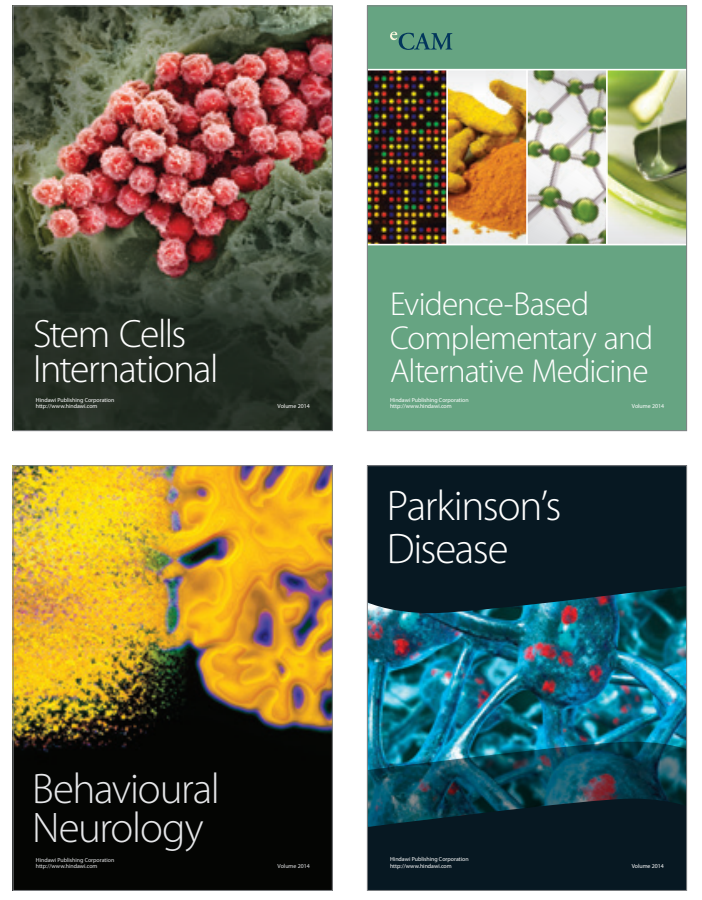
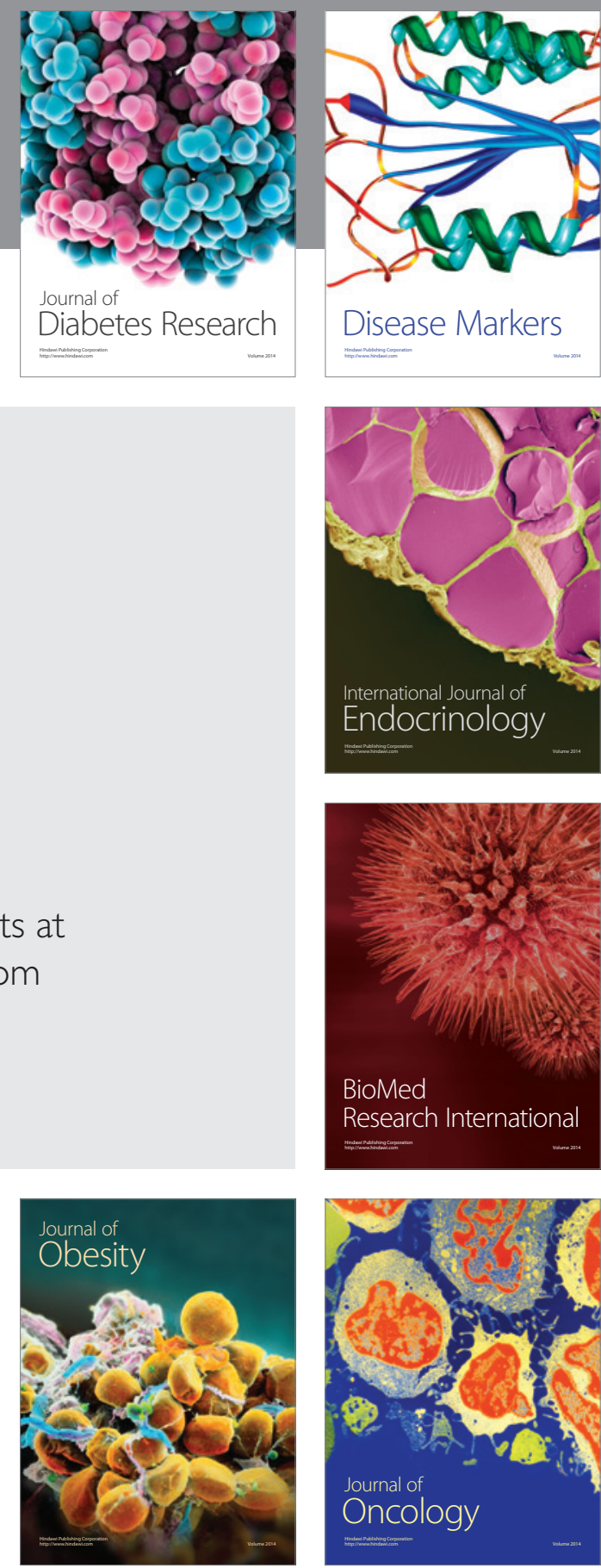

Disease Markers
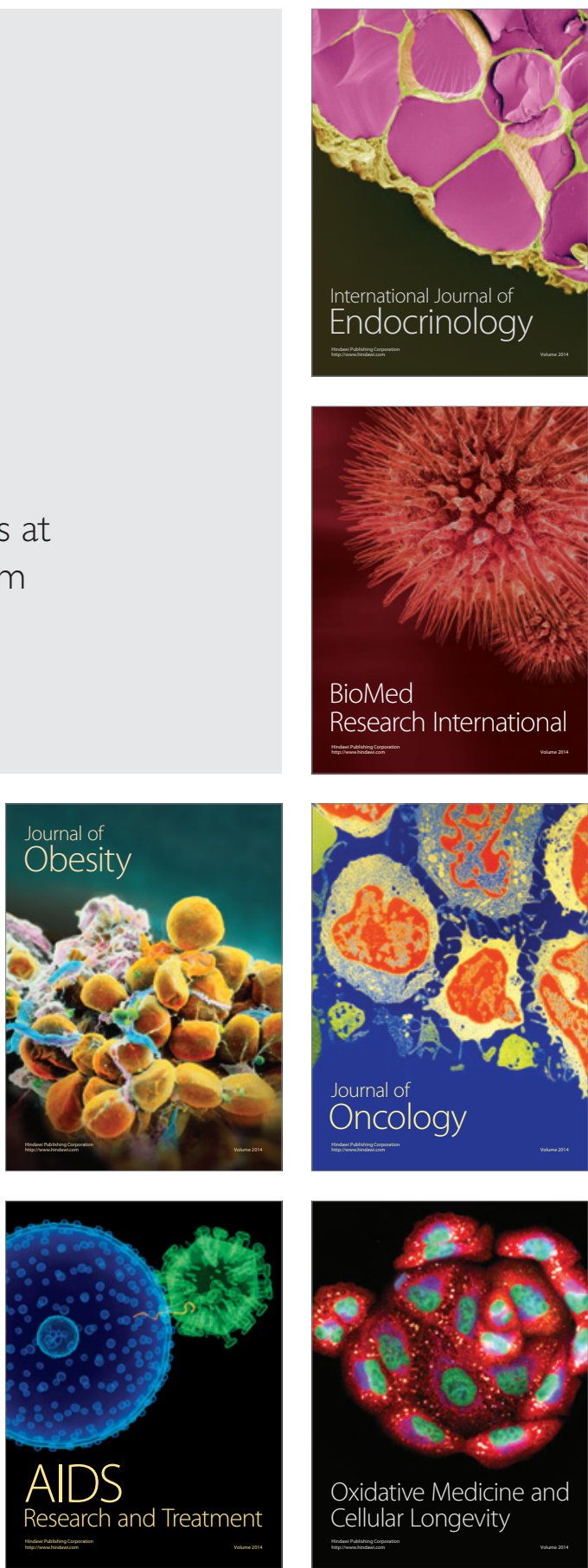